\title{
THORACIC ELECTRICAL BIOIMPEDANCE VERSUS THERMODILUTION IN PATIENTS POST OPEN-HEART SURGERY
}

\author{
Pavel Žáček, Pavel Kuneš, Eva Kobzová1, Jan Dominik
}

Charles University in Prague, Faculty of Medicine in Hradec Králové: Department of Cardiac Surgery; University Teaching Hospital in Hradec Králové: Department of Anaesthesia and Resuscitation ${ }^{1}$

\begin{abstract}
Summary: Thoracic electrical bioimpedance cardiography is a non-invasive, continuous and low-cost method of estimation of cardiac output and other haemodynamic parameters. Though subject to continuous technological refinement controversial opinions exist on its validity in subsets of critically ill patients, patients with heart disease or after cardiac surgery. A comparison study between thermodilution (TD) and bioimpedance (TEB) was performed in 28 patients undergoing elective cardiac surgery (CABG, aortic or mitral valve replacement or combined procedures). 128 pairs of cardiac index estimates at specific time points during 20 hours at the postoperative ICU were evaluated. A poor correlation $(r=0,26$, $\mathrm{p}<0,05$, bias $-0,071 \cdot \mathrm{min}^{-1} \cdot \mathrm{m}^{2}$, precision $+1,11 \cdot \mathrm{min}^{-1} \cdot \mathrm{m}^{-2}, 95 \%$ limits of agreement $-2,27-2,131 \cdot \mathrm{min}^{-1} \cdot \mathrm{m}^{-2}$ ) between TD and TEB cannot support the routine use of TEB monitoring in early postoperative period after open-heart surgery. Possible reasons of lack of agreement in this population are discussed. Further studies with technically improved bioimpedance cardiographs will be needed.
\end{abstract}

Key words: Cardiac output; Thermodilution; Electrical bioimpedance; Cardiac surgery; Intensive care unit

\section{Introduction}

Knowledge of changes of central haemodynamics in patients after cardiac surgery is of crucial importance for optimal therapy. Cardiac output, cardiac index (CI) and other indices characterizing left ventricular performance together with data of systemic and pulmonary vascular resistance give us information about the adequacy of oxygen transport - the most important function of cardio-pulmonary system.

Cardiac output and other derived parameters can be measured invasively by Fick method, dye dilution or thermodilution. Fick method and dye dilution are employed mostly in catheterization laboratories and are not suitable for clinical haemodynamic monitoring because of their technical difficulties. Thermodilution (TD) by means of right heart catheterization by Swan-Ganz pulmonary artery catheter is method most frequently used for routine and repeated bedside measurement of cardiac output despite its possible risks and costs. Cardiac output can be estimated non-invasively by Doppler echocardiography but the method is unsuitable for routine monitoring because it is timeconsuming and operator-depending.

Transthoracic electrical bioimpedance (TEB) is an attractive alternative providing non-invasive, continuous, real-time, time-unlimited and cheap monitoring of central haemodynamics. Though the technology has been refined in recent years controversies still do exist about its validity in clinical settings. The aim of this study was to determine the correlation and agreement between measurements of CI by means of TEB and TD and thus, in case of good correlation and agreement, indicate possible areas where thermodilution could be interchanged or replaced by bioimpedance.

\section{Material and methods}

The population studied were adult patients undergoing elective cardiac surgery at university cardiac surgery centre who had Swan-Ganz pulmonary artery catheter inserted either before induction of anaesthesia or in the course of operation. The decision about the right heart catheterization was upon anaesthesiologist's consideration based on patient's history, preoperative status and haemodynamic situation in the course of operation. The study was approved by the institutional Ethics Committee.

A total of 37 patients representing the usual incidence of cardiac procedures were monitored non-invasively by thoracic bioimpedance cardiograph. Ten patients were excluded of the cohort because of cardiac pacing (4), motoric disturbance (3) and low-quality impedance signal (3). Finally 28 patients were enrolled in the study having undergone following procedures: coronary revascularization (CABG - 19, including 1 miniinvasive coronary bypass grafting - MIDCAB), aortic valve replacement (4), mitral valve replacement (1) and combined procedures - aortic 
valve replacement with coronary revascularization (3). All patients were in sinus rhythm. All but one were intubated and artificially ventilated at the beginning of the monitoring period and were intentionally extubated no sooner than 4 hours after the arrival at ICU.

Thermodilution measurements were performed upon the arrival of the patient from operation room to ICU and then after 4, 8, 12 and 20 hours respectively. The value of CI estimate was the average of four consecutive injections of saline solution of room temperature. If any of the trials differed more than 10 percent it was deleted and additional injection was performed. The measurements were processed, stored and printed by the Marquette Electronics Inc. software.

Thoracic electrical bioimpedance measurements were performed in a way of continuous monitoring by non-invasive bioimpedance cardiograph Hotman AH/HHC (Hemo Sapiens, Irvine, Ca, USA). Eight solid gel electrodes were applied on the skin at the area of neck and thorax according to the scheme (Fig. 1). The bioimpedance cardiograph displayed the real-time continuous CI estimate as well as other haemodynamic parameters (respiratory rate, heart rate, stroke index, non-invasive blood pressure, end-diastolic index, ejection fraction, left stroke work index, inotropic state index, ejection phase contractility index, thoracic fluid conductivity). All measured data were stored by the cardiograph in a form of patient's record.

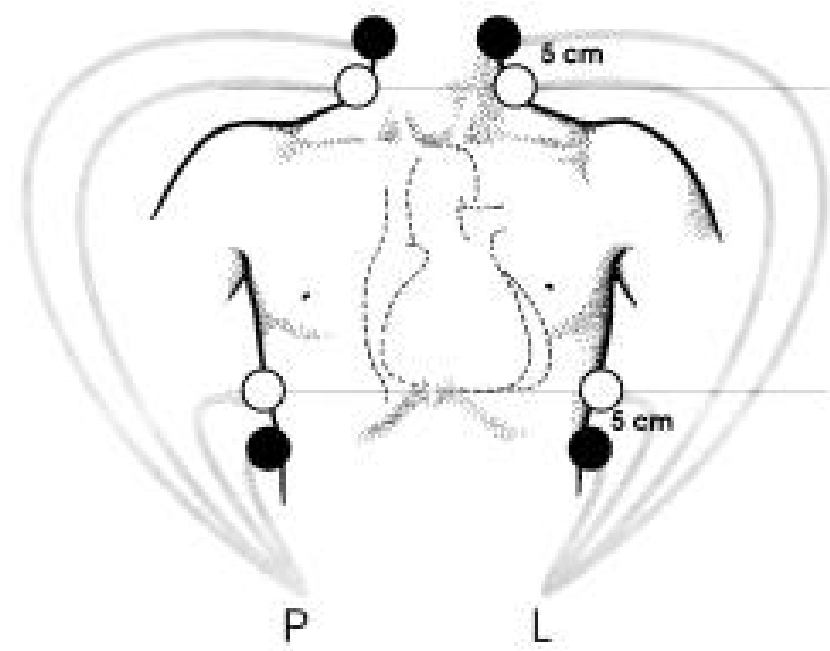

Fig. 1: Placement of TEB electrodes (black - current electrodes, white - sensing electrodes).

From all measured parameters only CI estimates were studied. As the bioimpedance CI estimate results from slightly oscillating reading that is updated every 1 minute the average value of 15 minutes record at corresponding time points was taken as a counterpart to be paired with the thermodilution measurement.

The paired data were processed by Excel 8.0 software (Microsoft). The correlation coefficient $r$ was calculated between the methods and data analysis introduced by Bland-Altman was performed.

\section{Results}

Together 128 pairs of CI estimates (thermodilution/bioimpedance) were obtained $(25,26,27,26$ and 24 at each time point respectively). The range of readings was $1,3-6,7$ $1 . \mathrm{min}^{1} \cdot \mathrm{m}^{-2}$ (TEB) and 1,8 - 5,6 1. $\mathrm{min}^{-1} \cdot \mathrm{m}^{-2}$ (TD).

A correlation was sought between TD and TEB readings. The correlation coefficient $r$ calculated for all pairs of data obtained was $0,26, p<0,05$ (Fig. 2). Then a correlation was sought between specific subsets of data. The correlation coefficient for $\mathrm{CABG}$ patients only was $r=0,30, p<0,05$. On the same basis correlation was determined between paired measurements at specific time points $1-5$. In these subsets $r$ was determined 0,$25 ; 0,33 ; 0,23 ; 0,34 ; 0,21 ; p<0,05$ respectively, indicating thus the best between-method correlation in measurements 12 hours after the end of open-heart surgery.

CI TEB vs. TD

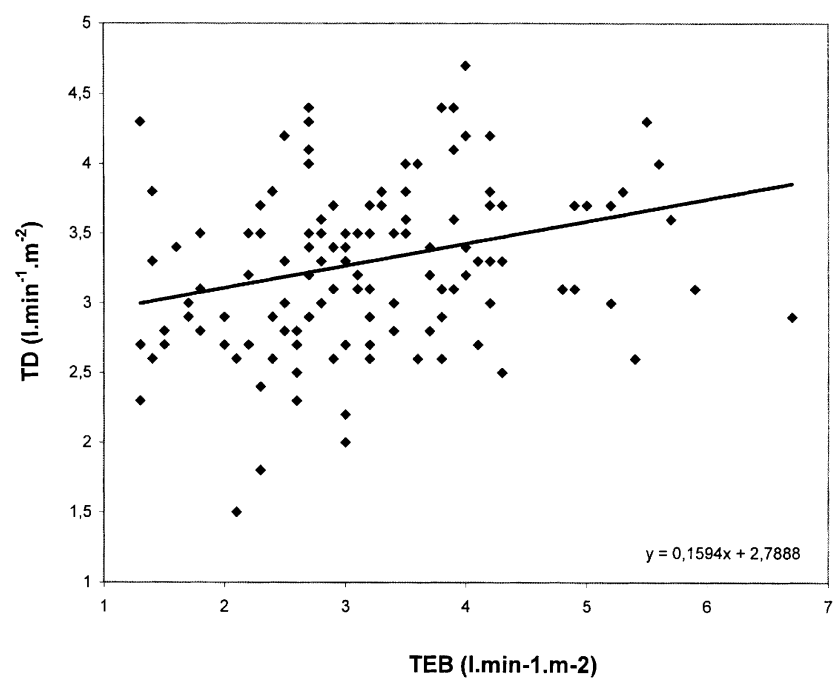

Fig. 2: Correlation coefficient between TEB and TD CI estimates during 20 hours after open-heart surgery $(r=0,26$, $\mathrm{p}<0,05 ; \mathrm{n}=128$ ).

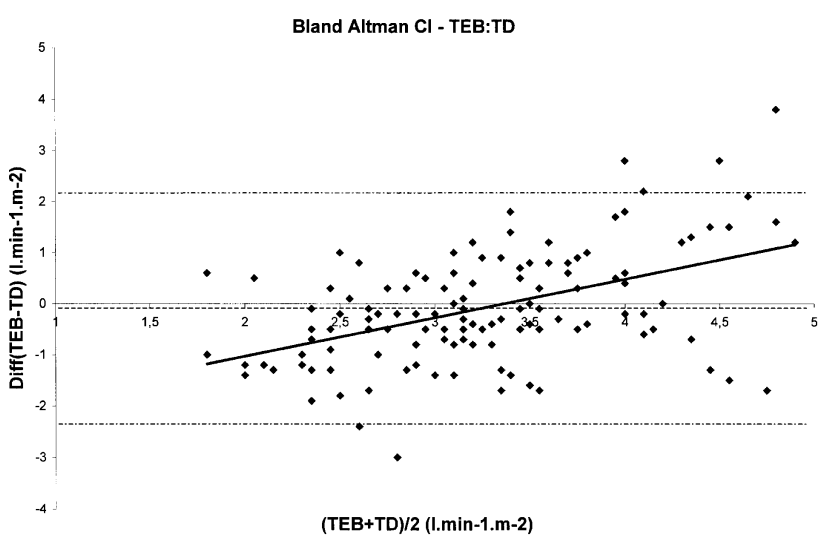

Fig. 3: Bland-Altman analysis of 128 pairs of CI measurements (TEB vs. TD); bias- $0,07+1,11 . \mathrm{min}^{-1} \cdot \mathrm{m}^{-2}$; $95 \%$ limits of agreement $-2,27-2,131 . \mathrm{min}^{-1} \cdot \mathrm{m}^{-2}$. 
A data analysis that was introduced in 1986 by Bland and Altman and since then has been widely used as the only correct procedure in determining the agreement of two methods, neither one of which is absolutely precise, was performed. The distribution of all data in BlandAltman's plot display bias $-0,071 \cdot \mathrm{min}^{-1} \cdot \mathrm{m}^{-2}$, with precision (SD) $\pm 1,11 . \mathrm{min}^{-1} \cdot \mathrm{m}^{-2}$. The $95 \%$ limits of agreement defined as \pm 2 SD were $-2,27-2,131 . \mathrm{min}^{-1} \cdot \mathrm{m}^{-2}$ (Fig. 3).

\section{Discussion}

Though the changes of impedance synchronous with cardiac cycle were noticed already by Vigoroux (1888) and Cremer (1907), the theoretical grounds were layed and first modern devices for measurement of thoracic electrical bioimpedance were constructed in U.S.A. in late 60-ties for the purpose of N.A.S.A. Nyboer in the beginnings of 50-ties described first equation for computation of stroke volume which was later modified by Kubicek in 60-ties:

$$
\mathrm{SV}=\operatorname{rho} \times\left(\mathrm{L} / \mathrm{Z}_{0}\right)^{2} \times \text { LVET } \times(\mathrm{dZ} / \mathrm{dt})
$$

where LVET $=$ left ventricular ejection time, $\mathrm{dZ} / \mathrm{dt}=$ maximal velocity of change of impedance during systole $(\mathrm{Ohm} / \mathrm{s})$.

In 1981 Sramek presented a new equation for computation of SV which eliminated blood resistivity and thoracic length:

\section{SV $=$ VEPT $x$ VET $x$ IC}

where VEPT = physical volume of electrically participating tissue calculated from sex, height and weight correlated to age, $\mathrm{VET}=$ ventricular ejection time, $\mathrm{IC}=$ index of contractility $\left(\mathrm{s}^{-1}\right)$.

Sramek's formula was later modified by Bernstein (1986) who introduced correction factor delta to eliminate some disproportions in patients with borderline weight.

Thorax represents an electrically inhomogeneous volume conductor. High-frequency electrical current of low intensity $(50-100 \mathrm{kHz}, 0,2-5 \mathrm{~mA})$ is distributed via two pairs of electrodes on the surface of the neck and at the level of diaphragm. Both the basic level of impedance and its dynamic changes are measured by two pairs of sensing electrodes situated inside the electrical field. The dynamic impedance changes are synchronous with heart rate and are caused predominantly by changes of descending thoracic aorta throughout the heart cycle. Descending thoracic aorta due to its longitudinal orientation is the main electrical current pathway in thorax. Changes of its impedance are caused by changes of its volume thus reflecting the cyclic intravascular changes of pressure originated in heart performance. Second contribution to the dynamic impedance signal $\mathrm{dZ}$ is the change of flowing blood conductivity with regard to its velocity. At the moment of highest velocity (systole) the blo- od displays the highest conductivity that is caused by most of the erythrocytes being aligned parallel to the stream.

The devices for measurement of transthoracic electrical bioimpedance have been substantially improved in the course of development. The dramatic onset of hardware and software sophistication enabled the modern bioimpedance cardiographs to be constructed as compact, easy-tohandle multifunctional devices suitable for longitudinal real-time bedside monitoring of central haemodynamics.

Due to its favourable characteristics TEB is frequently employed by investigators in anaesthesiology, gynaecology or nephrology. On the other hand, serious controversies still do exist about the validity of bioimpedance measurements in clinical conditions. The on-going efforts of investigators are motivated by the need of a device performing reasonably precise, non-invasive and cheap measurements. Works with different results were published comparing TEB with other modalities of cardiac output estimation in experimental model as well as in various patients populations.

Whereas the first trials were performed mostly on healthy volunteers confirming thus the basic concepts of the method a number of authors tried to validate bioimpedance cardiography in various clinical conditions against proven methods of $\mathrm{CO}$ estimation. The population for these studies was therefore recruited among those patients whose diagnostics and/or treatment necessitated the measurement of CO (thermodilution, indirect Fick, dye dilution, Doppler). Typically, patients undergoing diagnostic catheterization, open-heart surgery or staying at the ICU from various reasons were studied. The majority of these studies found an overall good correlation between methods $(r=0.65-0.9)$ and low bias values with varying values of precision. Shoemaker documented in multicenter trial the use of TEB in series of high-risk surgical patients with possibility of tracking the typical patterns of survivors vs. non-survivors via longitudinal bioimpedance cardiography monitoring $(1,2)$. Similarly, Bishop published good results in patients with gunshot wounds (3), Belardinelli in patients with ischaemic cardiomyopathy (4), Spiess during orthotopic liver transplantation (5), Northridge and Talarico in acute myocardial infarction, etc. $(6-9)$. The possibility of early detection of rejection episodes after heart transplantation was documented in the decrease of specific TEB acceleration index (10). On the contrary, others found only fair correlation between thermodilution and TEB and limits of agreement too wide for reasonable clinical application $(12,13)$.

The use of TEB in patients undergoing cardiac surgery is another appealing issue. The candidates for open-heart surgery - CABG predominantly - form relatively uniform group of patients who are well diagnosed, treated according to routine schemes and frequently with the use of pulmonary artery catheter. Hypothetical replacement of TD by TEB, if allowed under certain conditions, would mean a considerable diminishment of invasive burden as well as decrease of costs. However, the results of several studies are deeply controversial. Doering reports poor agreement in her 
series of 34 elective cardiac surgery patients (CABG, mitral valve replacement, combined valve and coronary surgery) being monitored non-invasely for 22 hours after operation (14). Thomas discourages the use of TEB in the first 12 hours after cardiac surgery (15). Similar negative conclusions were published by Spahn and Sageman $(16,17)$ whereas good correlation was experienced by Ferraro, Hraška, Schwann and recently in a multicenter COST study $(18$ - 20).

Despite controversial opinions on validity of TEB in clinical settings there is an agreement in defining the areas where TEB due to its inherent drawbacks is unsuitable for use. These are sepsis, tachycardia over $>180 / \mathrm{min}$, extreme obesity or height, excessive patient movement, dilatation of aorta, LBBB (21). Patients with aortic or mitral valve regurgitation are falsely underestimated because only forward flow is taken into consideration. The effect of improper position of lower pair of sensing electrodes on the $\mathrm{CO}$ estimate was demonstrated by Jewkes (22).

On the other hand, it has to be reminded that thermodilution is not a reference method and bears a lot of inherent imprecision as well (23). It is known for underestimating in low-flow states. In general, the flow-dependent relation between the two methods remains unclear. While overestimation by TEB in low-flow states is claimed by some (12) and also in high-flow states by others (22), a systematic underestimation was also reported (16). We found almost linear underestimation at low flow and overestimation at high flow (Fig. 4).

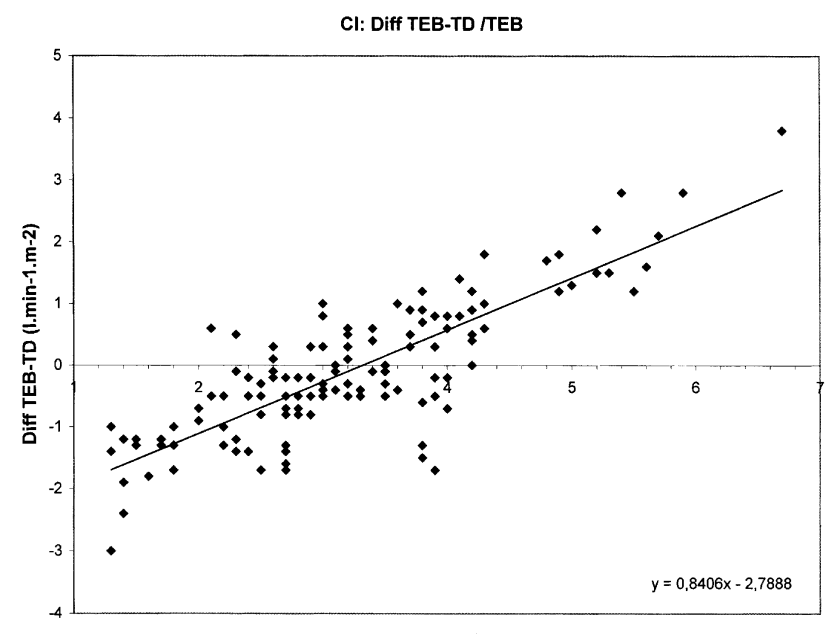

TEB $\left(1 \cdot \mathrm{min}^{-1} \cdot \mathrm{m}^{-2}\right)$

Fig. 4: Low-flow vs. high flow TEB readings - relation to simultaneous TD: low-flow TEB readings underestimate TD whereas high-flow TEB overestimates TD $(r=0,87, p<0,05$; $\mathrm{n}=128)$.

In our experience, transthoracic electrical bioimpedance monitoring can be easily accomplished providing comfortable real-time information and unlimited longitudinal record. Care has to be taken of correct placement of lower pair of sensing electrodes because the level of diaphragm lays more cranial in supine patients than it might by expec- ted. Patients who were $100 \%$ paced (via epimyocardial electrode placed at the time of operation) were not suitable candidates for TEB monitoring because aberrant QRS formation disabled correct detection of systole and led to erroneous CI estimate. Three MIDCAB patients were excluded from the study because of restlessness and motoric disturbances commonly seen after this type of procedure.

Nevertheless, correlation between two methods of CI estimation was poor what is expressed in $r=0,2 ; p<0,05$. The result did not change significantly when $\mathrm{CABG}$ patients were studied solely $(r=0,30, p<0,05)$ or only measurements from specific time points were examined separately $(r=0,21-0,34 ; p<0,05)$.

Bland and Altman introduced their statistical method in 1986 as the only correct tool in determining the agreement of two methods of which neither one is absolutely precise. The differences in readings by TD and TEB were plotted against the average of both methods. The between methods bias was very low $-0,071 . \mathrm{min}^{-1} \cdot \mathrm{m}^{-2}$. The precision however was $\pm 1,11 \cdot \mathrm{min}^{-1} \cdot \mathrm{m}^{-2}$. The $95 \%$ limits of agreement were 2,27 - 2,13 $1 . \mathrm{min}^{-1} \cdot \mathrm{m}^{-2}$, what represents interval unacceptable for clinical purposes.

It is evident that TEB technology encounters distinct problems in open-heart surgery patients. An acute dysbalance in thoracic fluid content after cardio-pulmonary bypass may be the leading cause. Different patterns of thoracic resistance in patients operated with vs. without cardio-pulmonary bypass, which were expressed shortly after cardiac surgery, were documented in the work of Máttar (24). The structural and functional changes of thorax, amount of fluid in pericardial and pleural cavities together with presence of chest tubes make the correct bioimpedance calculation difficult. Other misleading situations as arrhytmias, low-flow or high-flow states and artificial ventilation - the influence of which is poorly understood are frequently present after open-heart surgery.

\section{Conclusion}

Transthoracic electrical bioimpedance though controversially accepted is an established method for non-invasive monitoring of central haemodynamics. The bioimpedance cardiographs have been subject to continuous refinement of calculation algorithm. Newly released monitors are awaited for clinical evaluation. As numerous studies were performed in various clinical subsets using different types of bioimpedance cardiographs and employing different formulas (Kubicek, Sramek, Sramek-Bernstein) further technological improvement as well as clearly defined areas of clinical application still have to be sought. If justified by comparison study it would be very attractive modality due to its non-invasiveness, continuous real-time estimate and low costs in situations where information on central haemodynamics was needed but invasive approach was discouraged from multiple reasons. At this moment, however, our data cannot support this hypothesis. 


\section{References}

1. Shoemaker WC, Wo CC, Bishop MH et al. Multicenter trial of a new thoracic electrical bioimpedance device for cardiac output estimation. Crit Care Med 1994;22(12): 1907-12.

2. Shoemaker WC, Wo CC, Bishop MH et al. Noninvasive physiologic monitoring of high-risk surgical patients. Arch Surg 1996;131(7):732-7.

3. Bishop MH, Shoemaker WC, Shulesko J, Wo CC. Noninvasive cardiac index monitoring in gunshot wound victims. Acad Emerg Med 1996;3(7):682-8.

4. Belardinelli R, Ciampani N, Costantini C, Blandini A, Purcaro A. Comparison of impedance cardiography with thermodilution and direct Fick methods for noninvasive measurement of stroke volume and cardiac output during incremental exercise in patients with ischemic cardiomyopathy. Am J Cardiol 1996;77(15):1293-301.

5. Spiess BD, McCarthy RJ, Tuman KJ, Ivankovich AD. Bioimpedance hemodynamics compared to pulmonary artery catheter monitoring during orthotopic liver transplantation. J Surg Res 1993;54(1):52-6.

6. Northridge DB, Findlay IN, Wilson J, Henderson E, Dargie HJ. Non-invasive determination of cardiac output by Doppler echocardiography and electrical bioimpedance. Br Heart J 1990;63:93-7.

7. Talarico G, Saino A, Lotto A. Valutazione non invasiva dell'indice cardiaco e della frazione di eiezione nella cardiopatia ischemica. Confronto tra bioimpedenza toracica, termodiluizione e cineventricolografia. Minerva Cardioangiol 1992;40(6):203-9 (abstract).

8. Castor G, Molter G, Helms J, Niedermark I, Altmayer P. Determination of cardiac output during positive end-expiratory pressure - non-invasive electrical bioimpedance compared with standard thermodilution. Crit Care Med 1990;18(5):544-6.

9. Clancy TV, Norman K, Reynolds R, Covington D, Maxwell JG J. Cardiac output measurement in critical care patients: Thoracic Electrical Bioimpedance versus thermodilution. Trauma. 1991;31(8):1116-20.

10. Weinhold C, Reichenspurner H, Fulle P, Nollert G, Reichart B J. Registration of thoracic electrical bioimpedance for early diagnosis of rejection after heart transplantation. Heart-Lung-Transplant 1993;12(5):832-6.

11. Atallah MM, Demain AD. Cardiac output measurement: lack of agreement between thermodilution and thoracic electric bioimpedance in two clinical settings. J Clin Anesth 1995; 7(3):182-5.

12. Weiss S, Calloway E, Cairo J, Granger W, Winslow J. Comparison of cardiac out put measurements by thermodilution and thoracic electrical bioimpedance in critically ill versus non-critically ill patients. Am J Emerg Med 1995;13(6):626-31.

13. Woo MA, Hamilton M, Stevenson LW, Vredevoe DL. Comparison of thermodilution and transthoracic electrical bioimpedance cardiac outputs. Heart Lung 1991;20(4):357-62.

14. Doering L, Lum E, Dracup K, Friedman A. Predictors of between-method differences in cardiac output measurement using thoracic electrical bioimpedance and thermodilution. Crit Care Med 1995;23(10):1667-73.
15. Thomas AN, Ryan J, Doran BR, Pollard BJ. Bioimpedance versus thermodilution cardiac output measurement: the Bomed NCCOM3 after coronary bypass surgery. Intensive Care Med 1991;17(7):383-6.

16. Spahn DR, Schmid ER, Tornic M et al. Noninvasive versus invasive assessment of cardiac output after cardiac surgery: clinical validation. Cardiothorac Anesth 1990;4(1):46-59.

17. Sageman WS, Amundson DE. Thoracic electrical bioimpedance measurement of cardiac output in postaortocoronary bypass patients. Crit Care Med 1993;21(8):1139-42.

18. Ferraro S, D'Alto M, Maddalena G et al. Utilita della bioimpedenza nel monitoraggio del paziente in unita di terapia intensiva di cardiochirurgia: comparazione con la termodiluizione. Cardiologia. 1993;38(9):577-83.

19. Hraška V, Slezák J, Haruštiaková D et al. Komplexné porovnanie využitel’nosti a stanovenie limitácií neinvazívnej bioimpedančnej metódy s invazívnou termodilučnou metódou $v$ hemodynamickom sledovaní dospelých kardiochirurgických pacientov I - II. Noninvasiv Cardiol 1994;3(2):115-34.

20. Schwann NM, Napoli D, McNulty S, Torjman M, Audu P. Intraoperative comparison of a new thoracic bioimpedance device to thermodilution and echo for the determination of cardiac output. Anesth Analg 1997;84, SCA1-SCA127.

21. Young JD, McQuillan P. Comparison of thoracic electrical bioimpedance and thermodilution for the measurement of cardiac index in patients with severe sepsis. Br J Anaesth 1993;70(1):58-62.

22 Jewkes C, Sear JW, Verhoeff F, Sanders DJ, Foex P. Non-invasive measurement of cardiac output by thoracic electrical bioimpedance: a study of reproducibility and comparison with thermodilution. Br J Anaesth 1991;67(6):788-94.

23 Darovic GO. Hemodynamic Monitoring: Invasive and Noninvasive Clinical Application. 2nd ed. Philadelphia: W B Saunders, 1995:253-341.

24 Máttar JA, Batista ML, Ribeiro E, Tavares JR, Petrizzo A, Buffolo E. Application of bedside nonivasive method of body impedance analysis to assess changes in pre and postoperative period of cardiac surgery. Presented at VII. World Congress of Cardiology, Rio de Janeiro, 1998.

\section{Submitted January 1999 \\ Accepted April 1999}

\author{
MUDr. Pavel Žáček, \\ Charles University in Prague, \\ Faculty of Medicine in Hradec Králové, \\ Department of Cardiac Surgery, \\ 50005 Hradec Králové, \\ Czech Republic.
}

